\title{
A PROPOSED APPROACH INTEGRATING DLT, BIM, IOT AND SMART CONTRACTS: DEMONSTRATION USING A SIMULATED INSTALLATION TASK
}

\author{
J. Li $^{1^{*}}$, M. Kassem ${ }^{*}$, A.L.C. Ciribini ${ }^{2}$ and M. Bolpagni ${ }^{3}$ \\ ${ }^{I}$ Department of Mechanical \& Construction Engineering, Northumbria University, Newcastle, United Kingdom \\ ${ }^{2}$ School of Buildings Brescia, University of Brescia, Italy \\ ${ }^{3}$ Department of Architecture, Built Environment and Construction Engineering, Politecnico di Milano, Italy \\ * Corresponding authors
}

\begin{abstract}
The complementarity among Building Information Modelling (BIM), distributed ledger technology (DLT), smart contracts, and the Internet of Things (IoT) is increasingly acknowledged in industry reports and major national digital transformation initiatives. However, theoretical foundation and empirical evidence to ascertain such a prerogative are still very limited. This paper analyses the interactions between these technologies and proposes an approach that capitalises on their complementarity by linking the physical environment; the digital environment; agreements representing the contract; and the DLT environment. A simulated installation activity is used to verify the conceptual interrelations included in the proposed framework as a proof-of-concept. The simulation reveals how a mini smart contract - for a limited scope such as an installation activity work - can be executed within the proposed approach and how payments can be automated when project delivery is coupled with machine-readable BIM requirements and contract clauses. The paper also discusses the key limitations and challenges facing the adoption of the proposed approach and in particular the diffusion of smart contracts.
\end{abstract}

\section{Introduction}

The construction sector is becoming more digitalised with Building Information Modelling (BIM) being the main catalyst for digital transformation (Gerbert et al., 2016; Kassem and Succar, 2017; Chakravarty, 2018). Smart contracts is one of the key complementary concepts to BIM due to the increased capabilities in expressing construction project requirements in a computable manner, and in automation of contract clauses. The potential of BIM to digitalising the whole building lifecycle through the numerous model uses and use cases enabled by BIM creates further opportunities for integration between BIM, Internet of Things (IoT), and distributed ledger technology (DLT) (Ye et al., 2018). Emerging DLTs are proposed to address some the key concerns hindering collaboration in the construction industry and in particular trust with its inherent characteristics such as transparency, immutability, pseudonymity and resilience (Atzori, 2015; Swan, 2015; Biswas and Muthukkumarasamy, 2016; Kounelis et al., 2017). It has the potential to change the way businesses and organisations operate leading to better auditability and traceability (Atzori, 2015) encouraging more collaboration and information sharing (Winfield, 2018). IoT applications in construction are researched in supply chain management, construction management, and smart buildings and cities (Kassem and Li, 2017; Woodhead et al., 2018).
In an industry that has been hindered by lack of technological advancement, construction is slowly becoming digitalised but there are many challenges to be solved before true digital transformation is realised. The challenges begin at the procurement stage and cascade throughout the project and asset lifecycles. The aim of this paper is to propose an approach for the integration of DLT, BIM, IoT, and smart contracts in the construction industry and demonstrate how the complementarity of these technologies can aid in the industry's transformation. A proof-of-concept is demonstrated through simulation of a smart contract for an installation activity that takes performance metrics defined during procurement to automatically monitor progress of the activity resulting in an automated denial or approval of payment.

Section 2 defines the terms and concepts discussed throughout this paper. Section 3 explains the proposed approach for the integration of DLT, BIM, IoT and smart contracts. Section 4 demonstrates one part of the proposed approach within a simulated installation activity. Section 5 discusses the findings and limitations and presents the conclusions.

\section{Terms and Concepts}

\subsection{Distributed ledger technology (DLT)}

DLTs are append-only ledgers that chain blocks of information through a cryptographic hash function where transactions representing anything of value are grouped into blocks and 
verified and validated through a consensus mechanism such as a Proof-of-Work protocol that uses complex mathematics to solve equations across a distributed, decentralised, peer-topeer network (Kypriotaki et al., 2015; Swan, 2016; Turk and Klinc, 2017). The chaining and append-only nature makes the system secure and the cryptography ensures privacy of the data (Hamida et al., 2017). Blockchain, the underlying technology for cryptocurrency Bitcoin, is the most well-known DLT and has been in use since the launch of Bitcoin in 2009.

\subsection{Smart contracts}

Smart contracts are machine-readable pieces of code that conform to specific behaviours and are designed to selfexecute upon pre-set obligations being met (Boucher et al., 2017). They have the potential to transform how organisations transact and have the ability to negotiate without the need for human interaction. However, if smart contracts are to be considered as having the ability to replace entire traditional construction contracts, due to the complexity, flexibility and exercise of experienced judgement required in traditional construction contracts, they could result in being more expensive and more inefficient than traditional contracts (Sklaroff, 2017). For this reason, Mason (2017) suggests shortterm or instantaneous contracts are currently more suited to smart contracts adding that full automation is not possible at this time and focus should be on achieving semi-automation for now. One of the strengths of smart contracts is that they can act as a powerful evidentiary trail demonstrating agreements made by the parties (Frantz and Nowostawski, 2016; Cohn et al., 2017).

Non- and late-payment of contract terms is one of the construction industry's biggest challenges (Cardeira, 2015; Wang et al., 2017). Automated payments of fiat currency could be coded into smart contracts to protect contractors, subcontractors and the supply chain against insolvency from late payments (Wang et al., 2017) as well as reducing risk of underpayments, increasing efficiency and reducing pay-out time (Cohn et al., 2017). However, the industry requires payment reform before benefits can be truly realised (SEC Group, 2018).

The key barriers to implementation of smart contracts include maintenance of documentation, storage, interoperability, reliability of the data, confidentiality (Mason, 2017) and the complexity of coding smart contracts given the potential longevity required (Frantz and Nowostawski, 2016).

\subsection{Building Information Modelling (BIM)}

BIM is the current expression of digital innovation within the construction sector (Succar and Kassem, 2015), a combination of technologies, processes and policies (Succar, 2009). BIM is changing the way assets are designed constructed and operated (Eastman et al., 2011). Different uses of the information models extend over the whole asset lifecycle enabling designers, contractors, engineering, and facility managers to implement a digital approach to the design, construction and operation of assets.

\subsection{Internet of Things (IoT)}

The IoT is a paradigm where everyday objects can be equipped with identifying, sensing, networking and processing capabilities that will allow them to communicate with one another and with other devices and services over the internet to accomplish some objective. IoT is a system of interrelated smart devices with the ability to transfer data over a network without requiring human-to-human or human-to-computer interaction (Barnaghi et al., 2012).

\subsection{Digitalisation of the construction industry: interactions between key enablers}

It is no secret that the construction industry is going through a period of 'digitalisation' and 'digital transformation'. Digitalisation is a modernisation of processes and business models enabled by digital innovation (e.g. BIM, DLT, smart contracts, IoT). Digital transformation is an industry-wide effort that enables digitalisation by addressing the challenges preventing the diffusion of digital innovation at macro level. Benefits of digitalisation to the construction industry include boosting productivity, managing complexity, reducing project delays and cost overruns, and enhancing safety and quality.

The key challenges facing BIM adoption include lack of trust, poor collaboration and reluctance to share information (Farmer, 2016; Kinnaird and Geipel, 2018). Bolpagni et al., (2016) conducted a study on quasi-automation of requirements at procurement where those interviewed perceived benefits in digitalising the process. However, the authors found limited platforms with the ability to manage a BIM-based process and interviewees reported lack of readiness to adopt e-procurement citing issues of "trust $[\ldots]$, collaboration, inertia to change, security, confidence in data, quality assurance of information, share of risks and rewards" and understanding the benefits of such an approach as the biggest barriers (Bolpagni et al., 2016, p. 435).

DLT has the potential to solve some of these challenges through its 'immutable' ledger that is resistant to hacks and changes, can be accessed and updated in real-time, and offers reliability and transparency (Winfield and Rock, 2018). However, there are still many aspects to be addressed before the impact can be seen such as untested legal issues, the continuing need for clear and express contract terms, and mitigating measures that reduce the risk that parties take on unintended obligations and disputes (Winfield and Rock, 2018). DLT is "effective in those systems where the full synchronization of data and confirmation of the authorship of the performed actions is required" (Klyukin et al., 2018, p. 53).

DLT can help overcome a number of BIM issues such as ensuring incorruptibility of information through immutability and identification of the person making changes along with details of the changes to allow better recording and tracking of intellectual property and copyright, hence, resulting in increased confidence of the parties to collaborate (Stougiannos and Magneron, 2018). 
IoT devices (e.g. sensors, cameras, scanners) can be deployed not only in buildings but across the whole built environment. Once IoT is coupled with the digital asset (e.g. an information model) of a physical asset, they result in a digital twin that can be used for asset performance management where a digital twin is a virtual version of the physical asset (Woodhead et al., 2018).

\section{Proposed approach for the integration of DLT, BIM, IoT and Smart Contracts}

The proposed approach (Figure 1) for integration of the technologies is an extension of the work presented in Bolpagni (2018). It is conceived within the context of the UK construction industry but can be used in other contexts as the terminology derives from ISO 19650-1:2018 (ISO, 2018) (e.g. exchange information requirements, information container, appointing party). The first step in a procurement project is to compile the exchange information requirements (EIR) document upon which successful procurement relies (Lea et al., 2015). In order to integrate with DLT and smart contracts, clauses and requirements from the currently human-readable documentation (e.g. .doc, .pdf, .xls) need to be made machinereadable. Although such capabilities are generally limited in the construction industry, both academic literature and digital technologies are increasingly focusing on this challenge. For example, Patacas et al., (2016) proposed an approach for the automated checking of supply chain deliverables (data and documentation) against the requirements of the asset information requirements (AIR), defined in ISO 19650-1:2018 as the "information requirements [...] in relation to the operation of an asset" (ISO, 2018, p. 4). The proposed approach acknowledges the current inadequate level in the computerisation of project documents and their content. However, it simultaneously assumes that these challenges are transient given the on-going efforts of digitalisation and digital transformation within construction across many countries.

Several tiers of contractors and specialised trades throughout the supply chain answer to the EIR and comply with standards and regulations in the BIM Execution Plan (BEP). There is a pre- and a post-contract BEP; the version referred to in Figure 1 is the post-contract BEP. The BEP is usually not expressed in a machine-readable format; if it were, it would enable the automatic verification of planned deliverables against those of the EIR from a few standpoints (e.g. quality and schedule requirements). However, although this may be desirable, it is not the most urgent automation. Indeed, it is more important to automatically verify the compliance of the digital deliverables (expressed as 'Digital Environment' in Figure 1) with the requirements of the appointing party (i.e. EIR).

The deliverables of a project can be digital (i.e. information model, documentation and data) and physical (i.e. physical asset, goods and services) with the content of the BIM Execution Plan (BEP) first developed digitally and then physically. These are represented in Figure 1 as 'Digital Environment' and 'Physical Environment'. In the digital environment, the information model and supporting documentation and data are created and hosted in the information container throughout the life cycle of a built asset. The bi-directional arrows within the proposed approach show the flow of data in a construction project where the BEP, EIR and standards and regulations inform the development of the outputs in the digital environment supported where necessary by smart contracts.

Figure 1 Integration of DLT, BIM, IoT and Smart Contracts - the process of checking agreements against deliverables

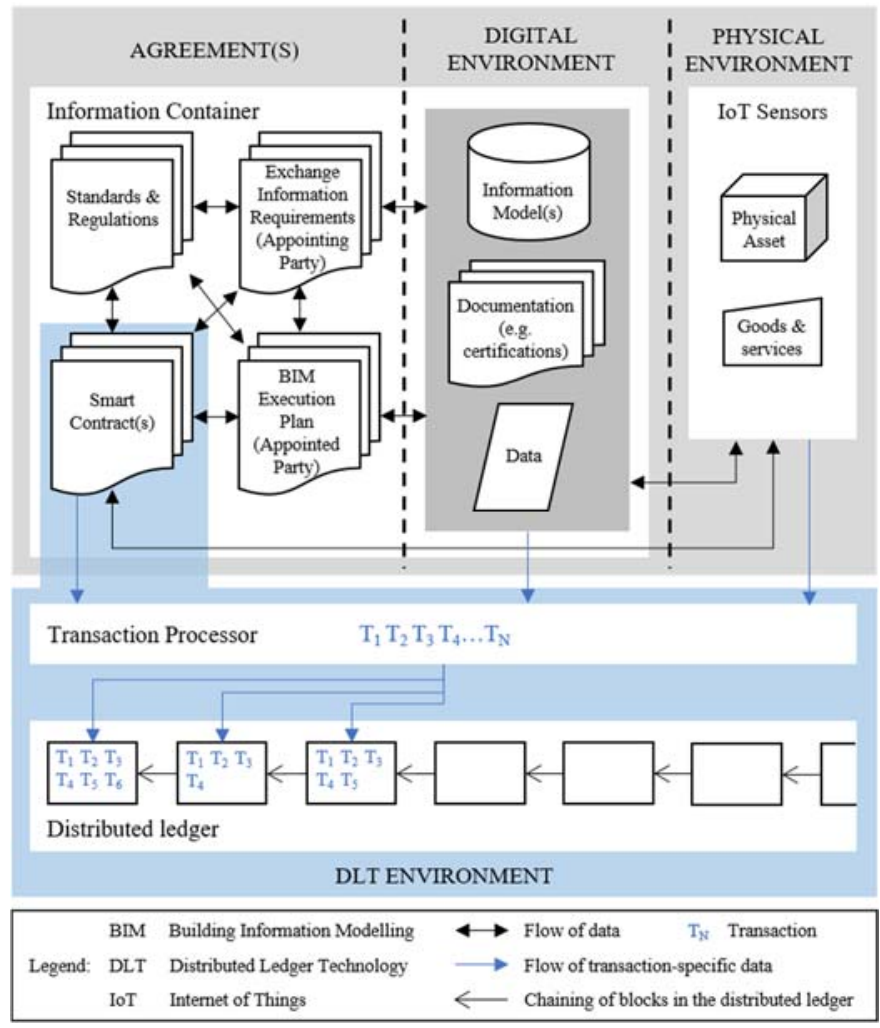

The one-directional arrows are transaction-specific data that are processed in the transaction processor (Turk and Klinc, 2017) then appended in blocks to the distributed ledger that represents an immutable digital record of the asset. Throughout the design and construction phases, it is possible to check the development of the project and its performance against requirements included in the EIR. The results of these checks are verified by transactions linked to smart contracts, that allow authorisation or denial of payments based on the outcomes. Both the digital deliverables and the transaction outcomes could be linked to the distributed ledger in a 'chained' manner (i.e. actual deliverables copied into the ledger) or 'unchained' manner (i.e. only fingerprints of actual deliverables copied into the ledger, not the deliverables themselves) (Turk and Klinc, 2017). In the proposed approach, the unchained method is adopted and this is exemplified in Figure 1 by the direct links between the 'Digital Environment' and the 'DLT Environment' consisting of only transaction data to be copied into the ledger. Other approaches may consider more direct links between the two environments. The approach also proposes an integration between the 'Physical Environment' 
and the 'DLT Environment' via IoT devices that verify in an automatic or automated way the outcomes (e.g. occurrence of events, quality, time) of site activities. The outputs of the IoT devices can be used as an input into the smart contract which can verify and/or deny payments. They can also be used to update the digital twin in the digital environment during the construction phase and to manage asset performance at the operations phase.

The proposed approach favours the adoption of performancebased contracts where payments are activated only if performance requirements are met (e.g. energetic, structural, acoustic). However, payment management through smart contracts face key challenges highlighted by McNamara and Sepasgozar (2018) as: information models representing a limited percentage (i.e. up to $45 \%$ ) of construction project measurable costs, and a need for alignment between information models, programmes, and cost models. Another consideration should be given to the flexibility required in traditional construction contracts that smart contracts do not account for (Sklaroff, 2017). For example, an experienced inspector would know if a wall has been constructed correctly and to pre-agreed specifications whereas sensors and devices currently lack exercising of such judgement.

\section{Simulating an installation activity}

An extract of the proposed approach is demonstrated as a proof-of-concept by simulating a project activity. The demonstration involves a simulated installation activity in a BIM-based project using a smart contract. The simulation demonstrates the coding of the smart contract in the DLT environment and the relationship with the BEP and EIR in the digital environment. The results from checking the performance of the installation in the physical environment are processed in a smart contract, which accordingly authorises or denies the payment. The smart contract was coded using PyCharm Community Editor 2018 (v2.4), which is free, opensource software. The simulation was part of the $\mathrm{PhD}$ research developed by Politecnico di Milano (Bolpagni, 2018) on the ongoing case study led by University of Brescia (DICATAM and DII departments) in collaboration with the School of Buildings in Brescia (ESEB), and building materials manufacturer, Weber Saint-Gobain. The simulation shows the functionality of automating the installation of an external thermal insulation composite system using a smart contract.

Typically, validation of product installations is done manually. No national or international standards exist to define installation steps, therefore, steps to perform the simulation were created using the manual of best practice published by the Italian external thermal insulation committee (CORTEXA, 2017) and discussions with three professionals from Weber Saint-Gobain. Computable values must be defined in order to create a smart contract and to check performances against contract requirements (Clack et al., 2016). The simulation translates EIR into code in order to create a smart contract with the aim of monitoring the installation process and linking the smart contract to the distributed ledger.
During physical delivery, each step could be automatically tracked using IoT devices to validate its successful installation and function leading to payments being executed without the need for human intervention (Mason, 2017). However, IoT technology maturity, cost and observability of benefits are yet to be reached before reliance on such technologies and diffusion occur at a wide scale. The current approach uses either manual checks or a combination of manual checks and 'BIM to field' (Mills, 2016) mobile technologies. Regardless of the means adopted to perform the checks, the outcomes of the checks denoting the performance during the physical delivery could be linked to a smart contract. In the proposed simulated installation activity, no IoT devices were included to measure the performance of the physical delivery. Instead, random values within reasonable ranges were used. Future simulations linking IoT devices and other reality capture technologies (e.g. photogrammetry) to the smart contract will be performed.

In the simulation, there are two types of steps: checks, which use the smart contract to check against requirements translated from the BEP and EIR; and installation or application, which is physical installation of items during the construction process done manually or by robotics where technology allows. The installation process is described in the following steps detailing the role of the smart contract where applicable.

[1] Check the flatness of the wall is less than $6 \mathrm{~mm}$ using laser scanner technology (LST): The flatness of the wall must be less than $6 \mathrm{~mm}$ (typically checked with a levelling bar or a grazing light) to ensure correct installation of the external thermal insulation panels. The if/then command reports whether wall flatness meets requirements to enable the panels to be fixed to the walls. If yes, the smart contract prints "flatness tolerance is within limits" and the activity can progress to the next step. If not, the smart contract prints "flatness tolerance is outside limits" and the activity cannot proceed, the work must be re-done and the check performed again until the activity can progress to the next step. Figure 2 demonstrates the smart contract code for this step.

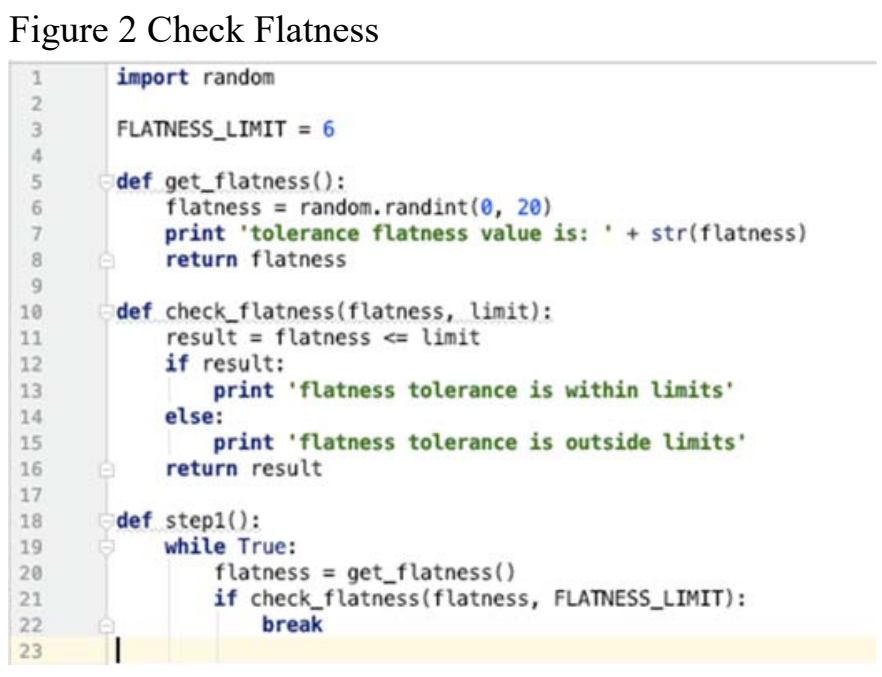


[2] Installation of humidity and temperature sensors on the external thermal insulation panels: No smart contract required. These IoT-enabled sensors are installed during the construction phase for use at the operations phase of the building to manage performance-based contracts. [3] Application of adhesive on external thermal insulation panels: No smart contract required. [4] Installation of the external thermal insulation panels from bottom to top: No smart contract required. [5] Check the panel offset is at least $25 \mathrm{~cm}$ using photogrammetry: Can be done using image recognition technology to confirm offset of the panel is at least $25 \mathrm{~cm}$ to avoid vertical joints. The if/then command in the smart contract checks the value of the offset (Figure 3) and reports whether it is inside or outside limits.

Figure 3 Check panel offset, openings, profiles, fibre meshes

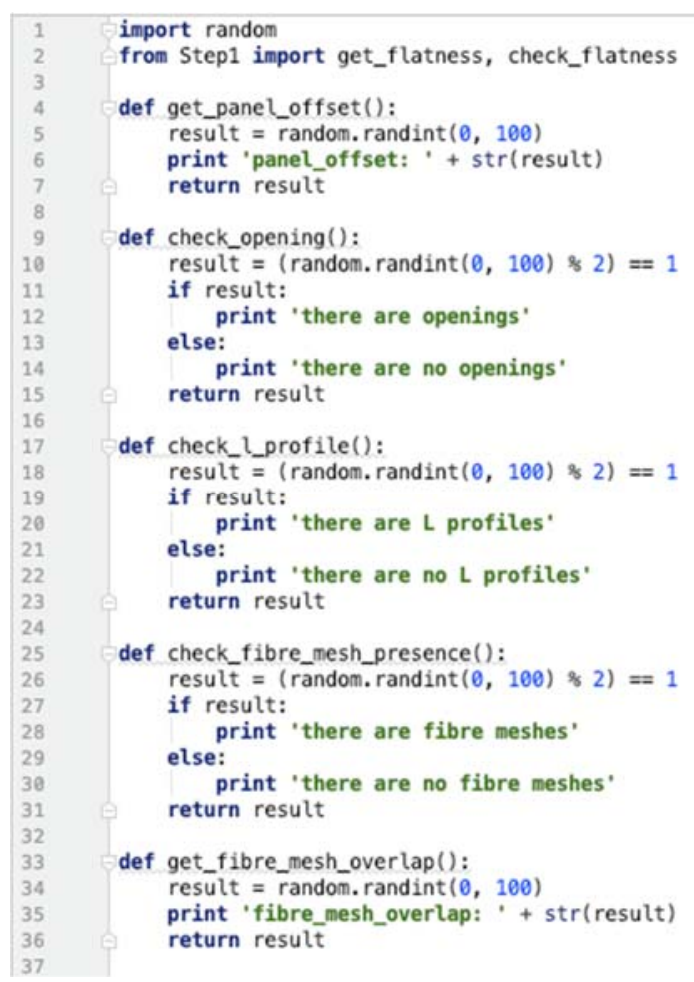

[6] Check if there are openings: image recognition technology checks for openings (e.g. doors, windows) and reports result via the smart contract (Figure 3). [7] Installation of $\mathbf{L}$ profiles (if required) in corners of openings: No smart contract required. [8] Check the presence of $L$ profiles (if required) using photogrammetry: If there are windows or other openings within the wall, the panels must include $\mathrm{L}$ profiles. Image recognition technology checks for L profiles and reports the result via the smart contract (Figure 3). [9] Check the flatness of the insulation system is less than $6 \mathrm{~mm}$ using LST: As this is the same coding required in Step [1], the same code is recalled for this step (Figure 2). [10] Installation of anchors: No smart contract required. Anchors are placed to fix the panels into the wall. [11] Check the anchors pattern against the project ( $T$ schema or $W$ schema) using photogrammetry: The anchors must follow a specific pattern
( $\mathrm{T}$ or $\mathrm{W}$ schema) that can be recognised using image recognition technology (Figure 4). If the pattern is wrong, they should be reapplied or replaced and rechecked.

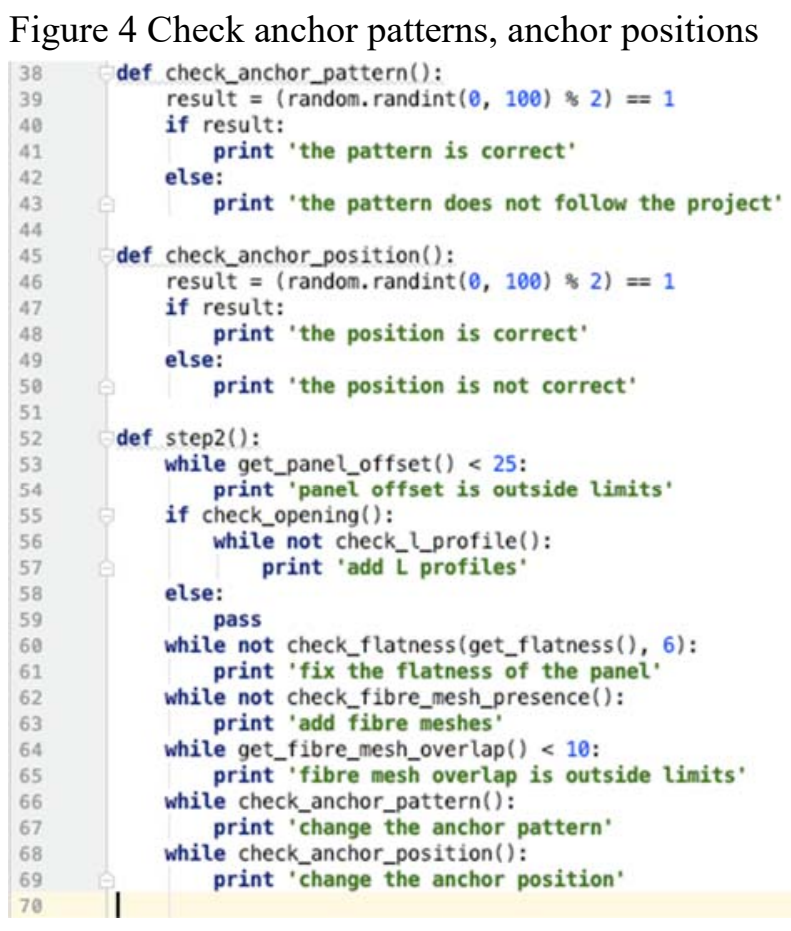

[12] Check the position of the anchors is aligned with the panel surface: The smart contract checks if the pattern follows the project specifications and if the anchor position is in compliance with requirements (Figure 4). If the position is wrong, they should be reapplied or replaced and rechecked. [13] Application of a base coat layer: No smart contract required. [14] Application of reinforcing fibre mesh: No smart contract required. [15] Check the presence of fibre meshes from top to bottom using photogrammetry: Image recognition technology can be used to confirm presence of fibre meshes and that they have been applied correctly (Figure 3). [16] Check the overlap between fibre meshes is at least $10 \mathrm{~cm}$ using photogrammetry: It is important to control that the fibre mesh has been installed correctly with at least an overlap of $10 \mathrm{~cm}$ (Figure 4). This check can be performed using image recognition technology and the smart contract can automatically check if the value is in compliance with requirements. [17] Application of a base coat: No smart contract required. [18] Check that the thickness of the base coat layer is at least $\mathbf{4 m m}$ : Same coding as in step 1 with different values. [19] Application of primer: No smart contract required. [20] Application of finishing layer of render: No smart contract required. [21] Final Flatness Check: a final check is made to confirm the flatness of the wall is less than $6 \mathrm{~mm}$ after completion of the installation task and the result reported by the smart contract (Figure 5). [21] Payment Permission: The smart contract checks payment permission (Figure 6). If all performance requirements are successfully addressed the smart contract returns a value of " 0 " allowing payment to be made (Figure 7). If they are not all addressed, the code provides the value " 29 " (or another random 
number that is not " 0 " indicating an error whose details will be included in an error manual to explain the type of error (e.g. payment not authorized), and payment is denied (Figure 8).

Figure 5 Check final flatness of wall

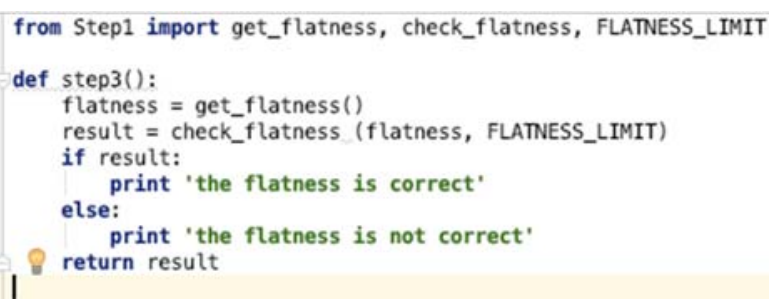

\section{Figure 6 Payment Permission}

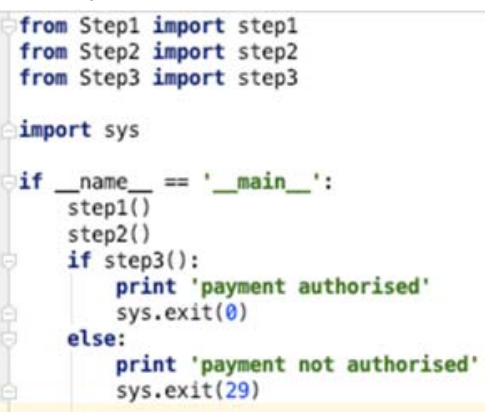

Figure 7 Authorisation of Payment

tolerance flatness value is: 6 flatness tolerance is within limits panel_offset: 26

there are no openings

tolerance flatness value is: 15

flatness tolerance is outside limits

$f$ ix the flatness of the panel

tolerance flatness value is: 2

flatness tolerance is within limits

there are fibre meshes

fibre mesh_overlap: 33

the pattern is correct

the position is correct

tolerance flatness value is: 0

flatness tolerance is within limits

the flatness is correct

payment authorised

Process finished with exit code 0

Figure 8 Denial of Payment

tolerance flatness value is: 3

flatness tolerance is within limits

panel offset: 34

there are no openings

tolerance flatness value is: 9

flatness tolerance is outside limits

$f i x$ the flatness of the panel

tolerance flatness value is: 5

flatness tolerance is within limits

there are fibre meshes

fibre mesh overlap: 100

the pattern does not follow the project

the position is correct

tolerance flatness value is: 20

flatness tolerance is outside limits

the flatness is not correct

payment not authorised

Process finished with exit code 29
In the simulated scenario, the smart contract did not authorise the payment as the flatness of the wall exceeded the accepted tolerance. This scenario shows how activities at the physical delivery can be coded into a smart contract. The performance criteria and thresholds used in the smart contact can be extracted from an approved and published information model within the information container.

\section{Discussion and conclusions}

The construction industry is facing many challenges. These include low productivity, poor regulation and compliance, lack of trust, inadequate collaboration and information sharing, and poor payment practices (Farmer, 2016; Hackitt, 2018; Woodhead et al., 2018). The digital transformation of the industry through BIM and more recently through DLT, IoT and Smart Contracts is currently being advanced as a solution to its problems. However, the integration and complementarity between these concepts and technologies is still a very novel challenge and has lagged interrogation to date. The aim of this paper was to address this gap by proposing a potential integration targeted at some of these key challenges, in particular, late payments, lack of trust and inadequate collaboration. A use case is presented showing how DLT with smart contracts supported by IoT device verification and BIM data can handle contractual clauses (particularly in performance-based contracts) could speed up the process of payment authorisation. The digitalisation eco-system integrating these technologies included four environments: DLT Environment including the smart contract; the Agreement(s) exemplifying the agreements made in EIR and BEP; the Digital Environment representing the project deliverables in terms of information model, data and documents; and the Physical Environment representing the actual delivery of the physical asset, goods and services where IoT-based verification and authentication of the performance can occur. The use case, although small in scope, showed that together these technologies play a complementary role and can execute the potential contractual clauses around a construction work (e.g. installation activity). The performance of the delivery of the physical asset can be detected by IoT devices or other electronic verification and authentication systems (e.g. reality capture). The data required to verify against can come from the information models, data and documentation approved and published at the digital delivery phase. The smart contract executes all clauses required to fulfil the contractual requirements for the considered work (e.g. installation activity) and accordingly authorises or denies the payment. Finally, the record of completion is appended to the distributed ledger, which can also record the payment events. The scenario investigated was limited due to its focus on one simple construction work. However, this example could be considered as one mini-contract out of thousands of mini-contracts making up a master smart contract - self-executing and transferring data as they complete and generating payment upon successful attainment of performance. The proposed work also shows the potential that could be achieved by deploying such technologies in a complementary manner. It also acknowledges the limitations and the challenges facing 
each of the technologies included in the proposed approach. Limitations and challenges associated with the technical integration of such technologies under the proposed approach were not addressed. Other regulatory challenges such as the limited adoption and diffusion of performance based-contracts were considered. Further challenges to the proposed approach and to the diffusion of smart contracts include: absence of a well-defined legislation on the management and enforcement of smart contracts; limited skills to interpret and translate legal prose into machine readable contracts; complexity of contracts network; and security concerns.

\section{Acknowledgements}

The authors would like to thank Arch. Lavinia Chiara Tagliabue, PhD and Rigert Seneja of UniBS DICATAM, Prof. Alessandra Flammini, Eng. Stefano Rinaldi and Eng. Flavio Simoncini of UNIBS DII, Eng. Davide Diotti from ESEB School of Buildings in Brescia, Dott. Fulvio Terminelli of Weber Saint-Gobain, Eng. Stefano Cantoni of Gexcel and I.T.I. Impresa Generale S.p.A for the support in developing the simulation illustrated in the paper lead by prof. Angelo Luigi Camillo Ciribini from UniBS DICATAM.

\section{References}

Atzori M (2015) Blockchain Technology and Decentralized Governance: Is the State Still Necessary? SSRN Electronic Journal 10.2139/ssrn.2709713.

Barnaghi P et al. (2012) Semantics for the Internet of Things: early progress and back to the future. International Journal on Semantic Web \& Information Systems 8(1): 1-21, 10.4018/jswis.2012010101.

Biswas K and Muthukkumarasamy V (2016) Securing Smart Cities Using Blockchain Technology. Proceedings of 2016 IEEE 18th International Conference on High Performance Computing and Communications; IEEE 14th International Conference on Smart City; IEEE 2nd International Conference on Data Science and Systems (Hpcc/Smartcity/Dss), Sydney, Australia, pp. 1392-1393, 10.1109/HPCC-SmartCityDSS.2016.178.

Bolpagni M (2018) Digitalisation of Tendering and Awarding Process: A Building Information Modelling (BIM)-Based Approach to Public Procurement Routes. Politecnico di Milano.

Bolpagni M et al. (2016) The European Client's Attitude Towards the Quasi-Automation of the Procurement Processes within a Digital Environment. Proceedings of the CIB World Building Congress 2016, Volume III: Building up business operations and their logic: Shaping materials and technologies (Saari, A. and Huovinen, P. (eds)). Tampere University of Technology, pp. 429-440.

Boucher P et al. (2017) How Blockchain Technology Could Change Our Lives: In-depth Analysis. European Parliament, PE 581.948.
Cardeira H (2015) Smart contracts and possible applications to the construction industry. New Perspectives in Construction Law Conference, Bucharest.

Chakravarty S (2018) Remodeling Construction Industry with Digitization, BIM and Reality Capture, Geospacial World. https://www.geospatialworld.net/article/how-re-modellingconstruction-digitizing-industry/ (accessed 30/10/2018).

Clack CD et al. (2016) Smart Contract Templates: foundations, design landscape and research directions. Pp. 1-15, http://arxiv.org/abs/1608.00771.

Cohn A et al. (2017) Smart After All: Blockchain, Smart Contracts, Parametric Insurance, and Smart Energy Grids. Georgetown Law Technology Review 1: pp. 273-304, https://perma.cc/TY7W-Q8CX.

CORTEXA (2017) Manuale per applicazione del Sistema a Cappotto. http://www.cortexa.it/index.php/it/informazionespecialisti/manuale-di-applicazione/manuale-perapplicazione-del-sistema-a-cappotto.html 16/10/2018)

Eastman C et al. (2011) BIM Handbook: A Guide to Building Information Modelling for Owners, Managers, Designers, Engineers, and Contractors, 2nd edn. John Wiley \& Sons, Inc., Hoboken, NJ.

Farmer M (2016) The Farmer Review of the UK Construction Labour Model: Modernise or Die. Construction Leadership Council. http://www.constructionleadershipcouncil.co.uk/wpcontent/uploads/2016/10/Farmer-Review.pdf.

Frantz CK and Nowostawski M (2016) From institutions to code: Towards automated generation of smart contracts. Proceedings - IEEE 1st International Workshops on Foundations and Applications of Self-Systems, FAS-W 2016, pp. 210-215, 10.1109/FAS-W.2016.53.

Gerbert $\mathrm{P}$ et al. (2016) Digital in Engineering and Construction: The Transformative Power of Building Information Modelling. The Boston Consulting Group http://futureofconstruction.org/content/uploads/2016/09/BCG -Digital-in-Engineering-and-Construction-Mar-2016.pdf.

Hackitt J (2018) Building a safer future - Independent Review of Building Regulations and Fire Safety: Interim Report. HM Government, Cm 9607.

Hamida EB et al. (2017) Blockchain for Enterprise: Overview, Opportunities and Challenges. ICWMC 2017: The Thirteenth International Conference on Wireless and Mobile Communications, pp. 83-88, https://www.iaria.org/conferences2017/ICWMC17.html.

ISO (2018) ISO 19650-1:2018 Organization and digitization of information about buildings and civil engineering works, including building information modelling (BIM) - Information management using building information modelling - Part 1: Concepts and Principles https://www.iso.org/standard/68078.html.

Kassem M and Li J (2017) Big Data Applications in Built Environment: Towards a Use Foundation Model. Lean and Computing in Construction Congress (LC3): Volume I Đ Proceedings of the Joint Conference on Computing in 
Construction (JC3), Heraklion, Greece, pp. 885-894. https://doi.org/10.24928/JC3-2017/0220.

Kassem M and Succar B (2017) Macro BIM adoption: Comparative market analysis. Automation in Construction 81(April): pp. 286-299, 10.1016/j.autcon.2017.04.005.

Kinnaird C and Geipel M (2018) Blockchain Technology: How the Inventions Behind Bitcoin are Enabling a Network of Trust for the Built Environment. ARUP https://www.arup.com/publications/research/section/blockcha in-technology.

Klyukin AA et al. (2018) Possibilities of New Information Technologies in the System of Urban Planning and Construction. Key Engineering Materials 771: pp. 49-55, https://doi.org/10.4028/www.scientific.net/KEM.771.49.

Kounelis I et al. (2017) Fostering consumers' energy market through smart contracts. 2017 International Conference Energy and Sustainability in Small Developing Economies (ES2DE), Funchal. P. 1-6,10.1109/ES2DE.2017.8015343.

Kypriotaki K et al. (2015) From Bitcoin to Decentralized Autonomous Corporations - Extending the Application Scope of Decentralized Peer-to-Peer Networks and Blockchains. Proceedings of the 17th International Conference on Enterprise Information Systems, Barcelona. SCITEPRESS Science and and Technology Publications, pp. 284-290, $10.5220 / 0005378402840290$

Lea $\mathrm{G}$ et al. (2015) Identification and analysis of UK and US BIM standards to aid collaboration. BIM 2015: International Conference on Building Information Modelling (BIM) in Design, Construction and Operations (Mahdjoubi, L. (ed.)). WIT Press, Bristol, UK, pp. 505-516, 10.2495/BIM150411.

Mason J (2017) Intelligent Contracts and the Construction Industry. Journal of Legal Affairs and Dispute Resolution in Engineering and Construction 9(3): p. 04517012, 10.1061/(ASCE)LA.1943-4170.0000233.

McNamara A and Sepasgozar SME (2018) Barriers and drivers of Intelligent Contract implementation in construction. 42nd AUBEA Conference 2018: Educating Building Professionals for the Future in the Globalised World, Singapore (Do K et al. (eds)). Curtin University, pp. 281-293.

Mills F (2016) What is BIM to Field? The B1M. https://www.theb1m.com/video/what-is-bim-to-field (accessed 31/12/2018).

Patacas J et al. (2016) Supporting building owners and facility managers in the validation and visualisation of asset information models (AIM) through open standards and open technologies. Journal of Information Technology in Construction 21: pp. 434-455, https://www.itcon.org/papers/2016_27.content.00686.pdf.

SEC Group (2018) Welcoming Support For Payment Reform From Ex-Infrastructure Tsar. https://secgroup.org.uk/welcome-support-for-paymentreform-from-ex-infrastructure-tsar/ (accessed 6/11/2018).

Sklaroff JM (2017) Smart Contracts and the Cost of Inflexibility. University of Pennsylvania Law Review 166: https://ssrn.com/abstract=3008899.
Stougiannos L and Magneron A (2018) BIM, Blockchain and the Smart Construction Contract. https://www.millerthomson.com/en/blog/breaking-groundmt-construction-law/bim-blockchain-smart-constructioncontract/ (accessed: 29/10/2018).

Succar B (2009) Building information modelling framework: A research and delivery foundation for industry stakeholders. Automation in Construction 18(3): pp. 357-375, 10.1016/j.autcon.2008.10.003.

Succar B and Kassem M (2015) Macro-BIM adoption: Conceptual structures. Automation in Construction 57: pp. 64 79, 10.1016/j.autcon.2015.04.018.

Swan M (2015) Blockchain: Blueprint for a new economy, O'Reilly Media Inc., Sebastoplo, CA, 10.1017/CBO9781107415324.004.

Swan M (2016) Blockchain temporality: Smart contract time specifiability with blocktime. Lecture Notes in Computer Science (including subseries Lecture Notes in Artificial Intelligence and Lecture Notes in Bioinformatics) 9718: pp. 184-196, 10.1007/978-3-319-42019-6_12.

Turk Ž and Klinc R (2017) Potentials of Blockchain Technology for Construction Management. Procedia Engineering 196: pp. 638-645, 10.1016/j.proeng.2017.08.052. Wang J et al. (2017) The outlook of blockchain technology for construction engineering management. Frontiers of Engineering Management 4(1): pp. 67-75, 10.15302/j-fem2017006.

Winfield M (2018) The Legal Frontier: Blockchain and Smart Contracts. BIMPlus. http://www.bimplus.co.uk/management/legal-frontier-

blockchain-and-smart-contracts/ (accessed: 1 February 2018).

Winfield M and Rock S (2018) The Winfield Rock Report: Overcoming the Legal and Contractual barriers of BIM. http://www.ukbimalliance.org/media/1185/the_winfield_rock report.pdf.

Woodhead R et al. (2018) Digital construction: From point solutions to IoT ecosystem. Automation in Construction 93(May): pp. 35-46, 10.1016/j.autcon.2018.05.004.

Ye Z et al. (2018) Cup-of-Water theory: A review on the interaction of BIM, IoT and blockchain during the whole building lifecycle. 2018 Proceedings of the 35th International Symposium on Automation and Robotics in Construction (ISARC 2018), Berlin. Pp. 478-486, 10.22260/ISARC2018/0066. 